\title{
Complex Reoperation for Late Complications After Acute Type A Aortic Dissection Surgery
}

\author{
Guillermo Stöger, MD*, Matías Ríos, MD, Roberto Battellini, MD, PhD, Daniel Bracco, MD, \\ Vadim Kotowicz, MD
}

Department of Cardiovascular Surgery, Hospital Italiano de Buenos Aires, Buenos Aires, Argentina

\begin{abstract}
The correct management of acute Type A dissection continues to be a challenge. The primary goal is to save the patient's life. However, the decision regarding the surgical approach determines possible later complications. We present the case of a 59-year-old female patient with a past history of emergent surgery for acute Type A dissection treated by supracoronary ascending and aortic valve replacement 19 years previously. Later, in a second endovascular approach, the descending aorta was treated by a thoracic endoprosthesis. During follow-up a dilated aortic root and a Type I endoleak were observed, and complex reoperation was required. We performed a total aortic arch replacement with a 4-branched graft and a complete aortic root replacement using the Cabrol technique for the reinsertion of the coronary arteries. The mechanical aortic normally functioning valve was preserved. The patient was discharged $\mathbf{3 0}$ days postoperatively.

Copyright $\odot 2015$ Science International Corp.
\end{abstract}

\section{Key Words}

Aortic root aneurysm - Reoperation after Type A dissection - Complication Type A dissection

\section{Introduction}

It is well known that in acute Type A aortic dissection preventing mortality determines the emergency surgical tactic. The aim is perioperative

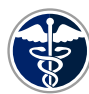

Fax +1 2037853552

E-Mail: aorta@scienceinternational.org

http://aorta.scienceinternational.org (c) 2015 AORTA

Published by Science International Corp. ISSN 2325-4637

Accessible online at: http://aorta.scienceinternational.org patient survival. The decision regarding the technique to be used depends on the center and the surgeon's experience, as well as on the patient's clinical condition.

Valvular replacement or resuspension associated with replacement of the ascending aorta (AAR) alone has been demonstrated to be a safe and fast strategy, but there is no doubt that leaving the dissected aortic root may lead to numerous complications [1, 2]. The incidence of reoperation after repair of Type A aortic dissection is 5.4 to $18 \%$ [3]. The combination of valve and aortic root replacement eradicates proximal reoperations when it is made in the first instance.

Several mechanisms may be involved in late complications: progressive aortic valve regurgitation, increased dilation of the preserved aortic root [3], dilation of non-resected distal aorta, aneurysms of the false lumen, and pseudoaneurysm formation. We present the case of a patient who underwent first an aortic valve replacement (AVR) and an AAR due to acute Type A aortic dissection in 1992. Eleven years later an endograft was placed in the descending thoracic aorta due to chronic dissection. During patient follow-up, dilation of the aortic root and Type I endoleak were also observed. Our final approach was total aortic arch replacement with reimplantation of the supra-aortic vessels and an aortic root replacement with a Cabrol procedure preserving the mechanical aortic valve.

\footnotetext{
* Corresponding Author:

Guillermo I. Stöger, MD

Cardiovascular Surgery Department

Hospital Italiano de Buenos Aires

Juan D. Perón 4190 (C1199ABD) Buenos Aires, Argentina

Tel.: +05411 4959 0200; Fax: +05411 4959 5804;

E-Mail: guillermo.stoger@hospitalitaliano.org.ar
} 

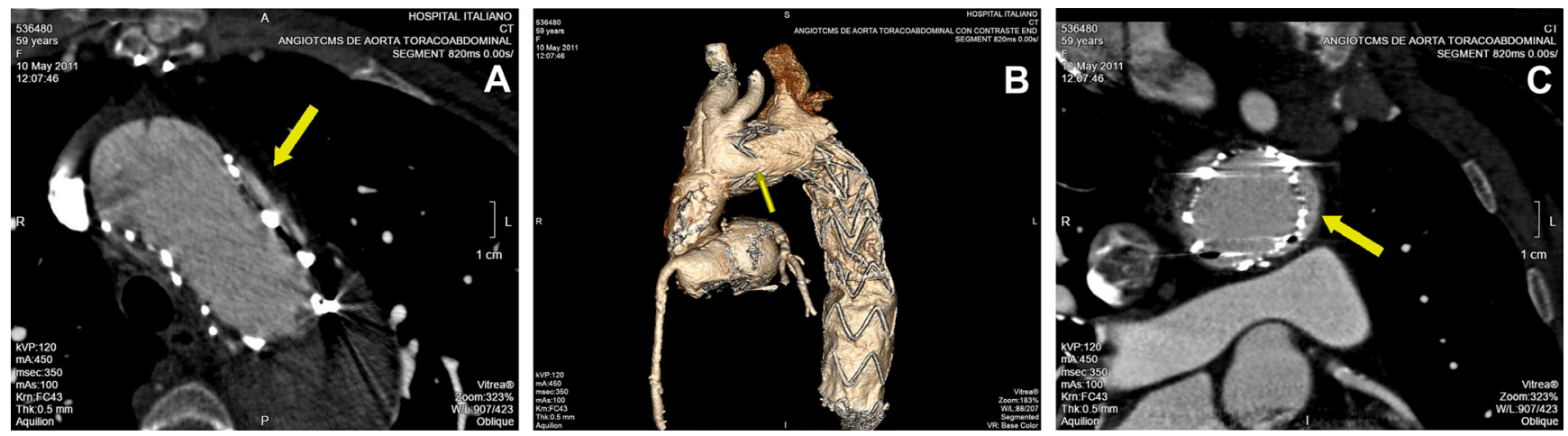

Figure 1. Preoperative computed tomographic scan. Panel A. Aortic arch with Type la endoleak (arrow). Panel B. Another view of the endoleak (arrow). Panel C. Dilated aortic root $(60.5 \mathrm{~mm})$ and descending aorta endoprosthesis with evidence of Type 1A proximal leak (arrow).

\section{Case Presentation}

A 59-year-old female was admitted in 2011 to our institution for chronic back pain. The patient had a history of aortic valve and supracoronary aorta replacement with a mechanical prosthesis $\mathrm{N}^{\circ} 23$ (Carbomedics ${ }^{\circledR}$, Sorin Group, Milan, Italy) and a Dacron graft $N^{\circ} 28$ in 1992, elsewhere. In 2003, because of refractory back pain, a computed tomography (CT) scan was done, and a progression of the dissection in the descending aorta was diagnosed. A thoracic endoprosthesis (Talent ${ }^{\circledR} 30 \times 130 \mathrm{~mm}$, Medtronic, Minnesota, USA) with occlusion of the left subclavian artery was implanted. In a CT control in 2005, a 1-cm distal migration of the endoprosthesis was observed leading to a Type I endoleak. A Talent ${ }^{\circledR}$ proximal cuff of $34 \mathrm{~mm}$ plus a distal extension of $32 \times 150 \mathrm{~mm}$ were placed to deal with it. During later follow up, the aortic root showed a stable $50-\mathrm{mm}$ diameter for 5 years. In 2010, the root was $6.05 \mathrm{~cm}$, the thoracic aneurysm reached $6.4 \mathrm{~cm}$, and the Type I endoleak was still persistent (Figure 1) and the patient continued with pain. We planned a reoperation in April 2011.

The procedure was performed through a median resternotomy under cardiopulmonary bypass (CBP). This was instituted through right axillary and right femoral arterial cannulation, and right femoral vein cannulation with a long cannula (Edwards Lifesciences, Irvine, California, USA). Left heart venting through right superior pulmonary vein was added. The ascending aorta graft was clamped and antegrade cold crystalloid Bretschneider cardioplegia was first

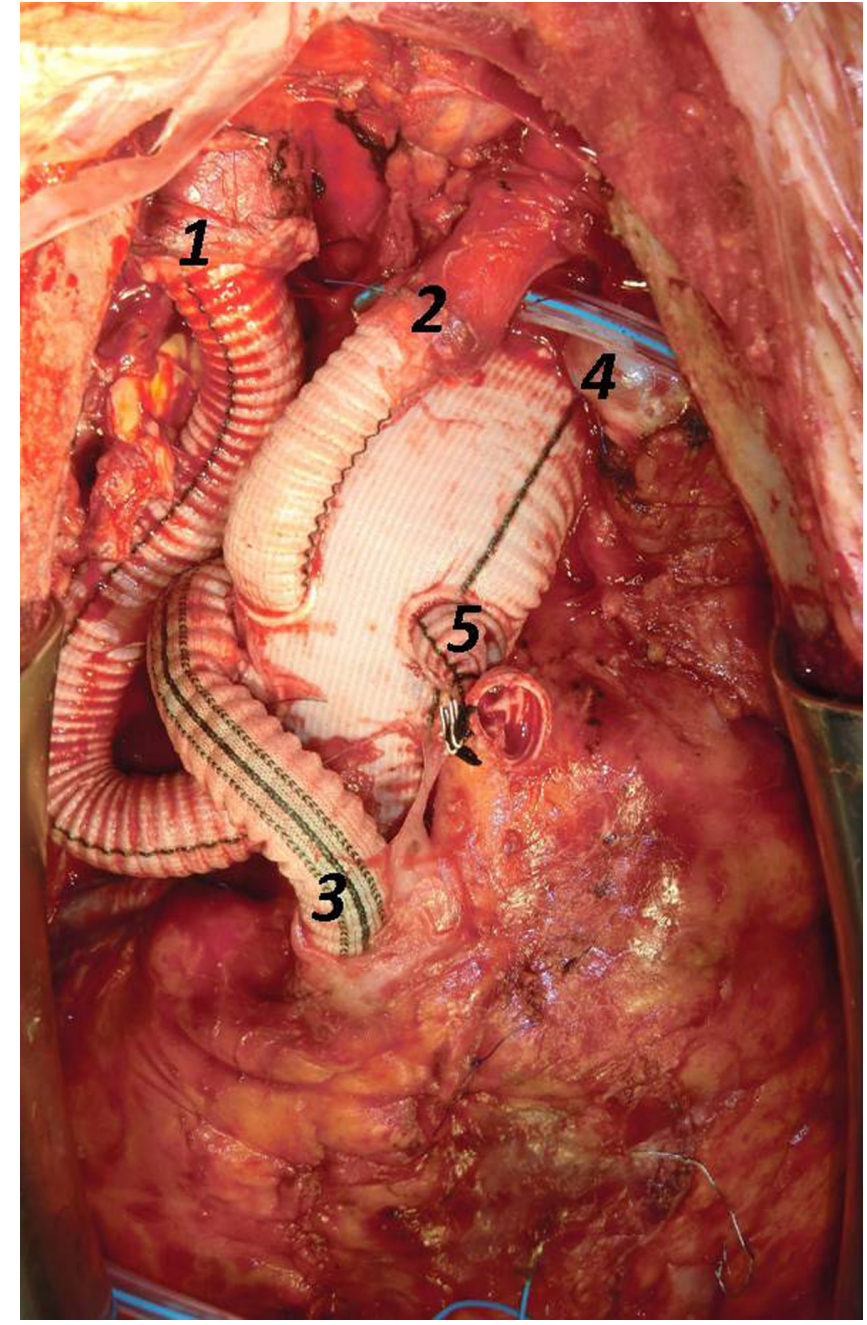

Figure 2. Completed procedure. Four-branched prosthesis: 1. brachiocephalic trunk; 2. left carotid; 3. Dacron No. 8 (Cabrol technique); 4. distal anastomosis; and 5. perfusion limb, tied. *Note: The side-to-side Cabrol anastomosis was done with the third limb of the graft. 
given, followed by cardioplegia via the coronary ostia after opening the Dacron graft. The graft was excised and the aortic root resected. When the temperature reached $20^{\circ} \mathrm{C}$, the aortic clamp was removed and low flow brain perfusion begun through the axillary artery, clamping the brachiocephalic trunk (BCFT) proximally and adding selective perfusion through the left carotid artery. Carbon dioxide flooding was used. The aortic arch was transected between the left carotid (LCA) and left subclavian artery (LSA). The proximal bare wires of the thoracic endostent were cut and the arch reconstructed suturing a 4-branched Dacron graft (30 mm, Hemashield ${ }^{\circledR}$, Maquet, Germany) with the endoprosthesis using 3.0 Prolene (Visi-black Prolene ${ }^{\circledR}$, Ethicon, New Jersey, USA), reinforced with a band of Teflon felt from outside. The new prosthesis was then clamped and lower body flow was restored. Both LCA and the BCFT were transected at their origins and anastomosed to the 8-mm branches in an end-to-end fashion. The proximal aortic anastomosis was performed by suturing the proximal end of the 4-branched graft directly to the old mechanical valve ring in a continuous fashion using 3.0 Visi-black Prolene. The coronary reimplantation was done with a modified Cabrol technique, by using the proximal limb of the graft, cut at $3 \mathrm{~mm}$ of its origin for the sideto-side anastomosis (Figure 2). The perfusion limb of the graft was cut and oversewn. A needle vent was inserted for deairing and reperfusion was made. After weaning from CBP, protamine was administered, and the procedure was completed in a routine fashion. Aortic clamp time was 196 minutes, the total CPB time was 241 minutes, and the low flow perfusion time was 47 minutes.

After the operation, the patient had atrial fibrillation without hemodynamic repercussion, and later bilateral pneumonia developed, requiring 14 days of antibiotic treatment. The patient was discharged 30 days postoperatively. Before discharge, a new CT scan was performed (Figure 3).

\section{Discussion}

Acute Type A aortic dissection optimal treatment remains controversial. Different surgical approaches determine the short and long-term patient survival. The choice of the correct surgical strategy is generally

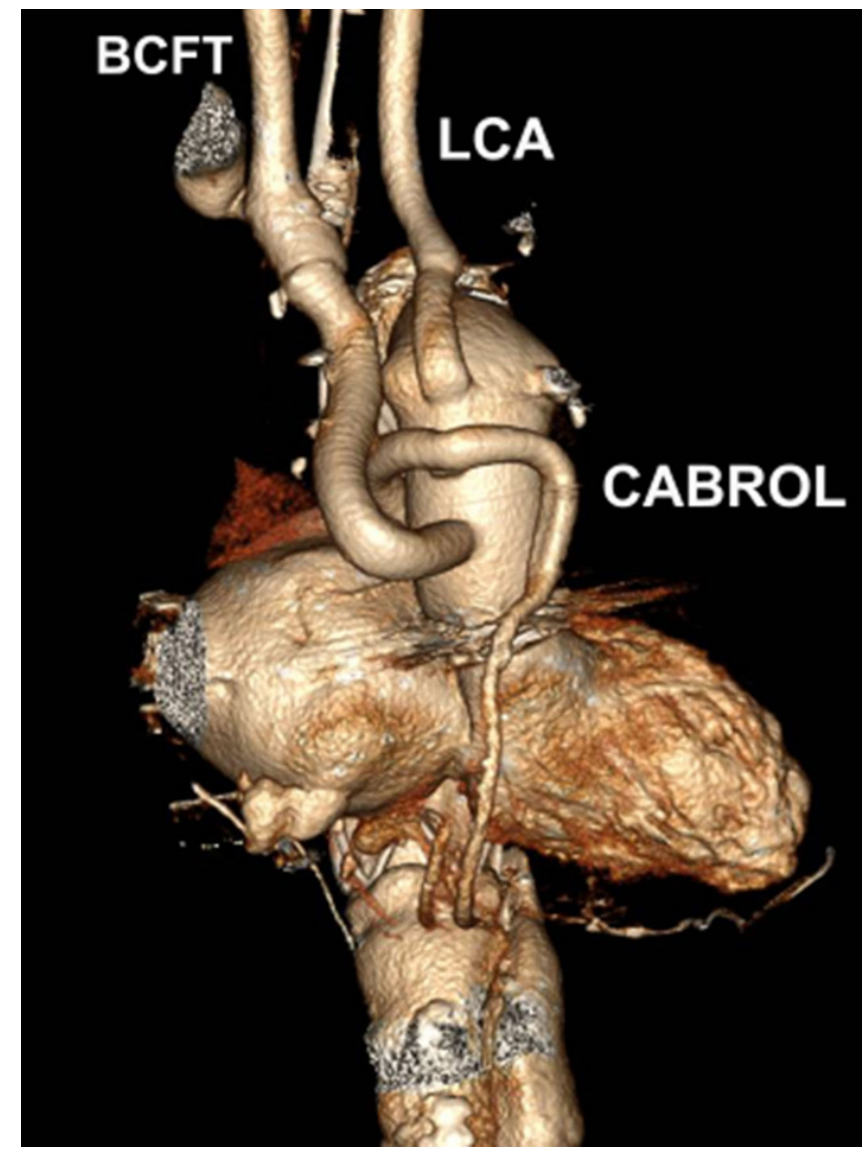

Figure 3. Postoperative $C T$ scan before discharge. BCFT = brachiocephalic trunk; LCA = left carotid artery; $C A B R O L=$ coronary arteries reimplantation (Cabrol technique).

determined by the individual risk of each patient and the surgeon's experience [4].

Halstead and Rylski $[3,5]$ rethink indications after finding a higher incidence of reoperation after Type A dissection in patients undergoing valve replacement separately from the ascending aorta against the group who underwent Bentall procedure, who did not require reintervention. The average time between the first surgery and the development of new aortic pathology was 4 years. In our case, it was 19 years. For the latter [5], the main causes of reoperation were incomplete resection of the tear, failure of obliteration of the false lumen, and severe aortic regurgitation. Pseudoaneurysm development and dehiscence of the suture line were also important causes of reoperation.

In our case, we decided to perform a Cabrol tech- 
nique to treat the root due to the distance between coronary ostia [6]. We also showed, like Leacche [7], the advantage of avoiding the explantation of a well-functioning valve prosthesis, reducing the magnitude of the operation. We finally demonstrated the use of a Dacron 4-branched graft with the endoprosthesis incorporated into the distal anastomosis.

\section{Conflict of Interest}

The authors have no conflicts of interest relevant to this publication.

\section{Comment on this Article or Ask a Question}

\section{References}

1. Kazui T, Washiyama N, Bashar AH, Terada $\mathrm{H}$, Suzuki T, Ohkura K, et al. Surgical outcome of acute type A aortic dissection: Analysis of risk factors. Ann Thorac Surg. 2002;74:75-81. DOI: 10.1016/S00034975(02)03603-2

2. S Leontyev, M Misfeld, M Borger, Gindensperger O, Seeburger J, Lehmann, et al. Aortic arch reoperation following replacement of the ascending aorta. Thorac Cardiovasc Surgeon. 2011;59:MO65. DOI: 10.1055/s-0030-1269333

3. Halstead JC, Spielvogel D, Meier DM, Rinke S, Bodian C, Malekan R, et al. Composite aortic root replacement in acute type A dissection: Time to rethink the indications? Eur J Cardiothorac
Surg. 2005;27:626-633. DOI: 10.1016/j. ejcts.2004.12.059

4. Kobuch R, Hilker, M, Rupprecht L, Hirt $\mathrm{S}$, Keyser A, Puehler T, et al. Late reoperations after repaired acute type $A$ aortic dissection. J Thorac Cardiovasc Surg. 2012;144:300-307. DOI: 10.1016/j. jtcvs.2011.08.052

5. Ryski B, Beyersdorf F, Blanke P, Boos A, Hoffman I, Dashkevich A, et al. Supracoronaty ascending aortic replacement in patients with acute aortic dissection type A: What happens to the aortic root in the long run? J Thorac Cardiovasc Surg. 2013;146:285290. DOI: 10.1016/j.jtcvs.2012.07.013

6. Perriello J, Battellini R, Boretti J, Climente J. Tratamiento del aneurisma de aorta ascen- dente a 12 años de un reemplazo valvular aórtico. Hospital Privado de la Comunidad. Mar del Plata, Buenos Aires, Argentina. 2001.

7. Leacche M, Umakanthan R, Byrne JG. Prosthetic valve sparing aortic replacement: An improved technique. Interact CardioVasc Thorac Surg. 2008;7:919-921. DOI: 10.1510/icvts.2008.182915

Cite this article as: Stöger $G$, Ríos $M$, Battellini R, Bracco D, Kotowicz V. Complex Reoperation for Late Complications After Acute Type A Aortic Dissection Surgery. AORTA (Stamford). 2015;3(6):195-198. DOI: http://dx.doi. org/10.12945/j.aorta.2015.15.019 